\title{
Garlic Burn in a Patient with Trigeminal Neuralgia: A Case Report
}

\author{
H. Huseyin Yilmaz ${ }^{\mathrm{a}}$ \\ Ozlem Gormez \\ Esin Hastar ${ }^{b}$ \\ Derya Yildirimb \\ Muge Cina Aksoyc
}

\section{ABSTRACT}

Garlic is an herb which has been used by many cultures for treating various health problems for centuries. Uncontrolled use of herbal remedies, known as alternative treatment methods, may lead to side effects and serious treatment complications. This study aimed to draw attention to complications related to alternative treatment methods and to review the literature in the light of this case.

A female patient who had been treated for trigeminal neuralgia was admitted to our clinic complaining of severe pain on the left side of her face. In anamnesis, the patient reported that she had applied garlic topically to this region. Extraoral examination revealed a broad cutaneous burn on the same region. According to a dermatology consultation, a treatment for cutaneous burns was applied and severe trigeminal neuralgia pain was eliminated with glycerol injection by an oral and maxillofacial surgeon. (Eur J Dent 2010;4:88-90)

Key words: Garlic burn; Trigeminal neuralgia; Herbal medicine.

- Associate Professor, Suleyman Demirel University, Faculty of Dentistry, Department of Oral Diagnosis and Radiology, Isparta, Turkey.

b Research Assistant, Suleyman Demirel University, Faculty of Dentistry, Department of Oral Diagnosis and Radiology, Isparta, Turkey.

c Research Assistant, Suleyman Demirel University, Faculty of Dentistry, Department of Oral and Maxillofacial Surgery, Isparta, Turkey.

Corresponding author: H. Huseyin Yilmaz SDU Dishekimligi Fakultesi Dogu Kampusu, 32260, Isparta, Turkey.

Phone: 00902462113272

Fax: 00902462370607

E-mail: hyilmaz@dishek.sdu.edu.tr, huseyinyenidyahoo.com

\section{INTRODUCTION}

Herbal medicinal products are highly popular. Garlic (Allium sativum L. Fam Liliaceae) is one of the best-researched and best-selling herbal remedies and is also commonly used as a food and a spice. Case reports have highlighted the possibility that use of garlic may cause allergic reactions lallergic contact dermatitis, generalized urticaria, angiedema, pemphigus, anaphylaxis and photoallergy), alteration of platelet function and burns when fresh garlic is applied on the skin, particularly under occlusive dressings. ${ }^{1}$ Only a few cases of garlic burn have been reported in the literature. ${ }^{2}$ 
Trigeminal neuralgia causes sudden, usually unilateral, severe brief stabbing recurrent pains in the distribution of one or more branches of the trigeminal nerve. ${ }^{3}$ Proper diagnosis is critical. Teeth have been extracted unnecessarily in some cases on the presumption the pain is of dental origin. Close collaboration between a dentist and neurologist is required for appropriate diagnosis. ${ }^{4}$

In this case report, a garlic burn in a patient with trigeminal neuralgia was presented.

\section{CASE REPORT}

An 80-year- old female patient was referred to our clinic with severe, lancinating pain which occurred intermittently on the left side of her face for a period of three years. This pain had been getting progressively worse for at least one year. According to her medical history, trigeminal neuralgia had been diagnosed by neurology and neurosurgery clinics and Carbamazepine (Tegretol $(\circledR)$ was applied. Because Carbamazepine did not provide significant relief, an alcohol injection was made in mental foramen by a dentist two years earlier. Following the alcohol injection, the pain began again after prodromal term for one year. On extraoral examination, a lesion with varying degrees of erythema, clear borders, crusting surface tissue formation which was spreading through cheek, commissure and mandibular region on the left side of her face was determined (Figure 1). The patient could not bear her pain and had applied crushed garlic, wrapped in cloth, to her face for an hour at the recommendation of her neighbor two days prior.

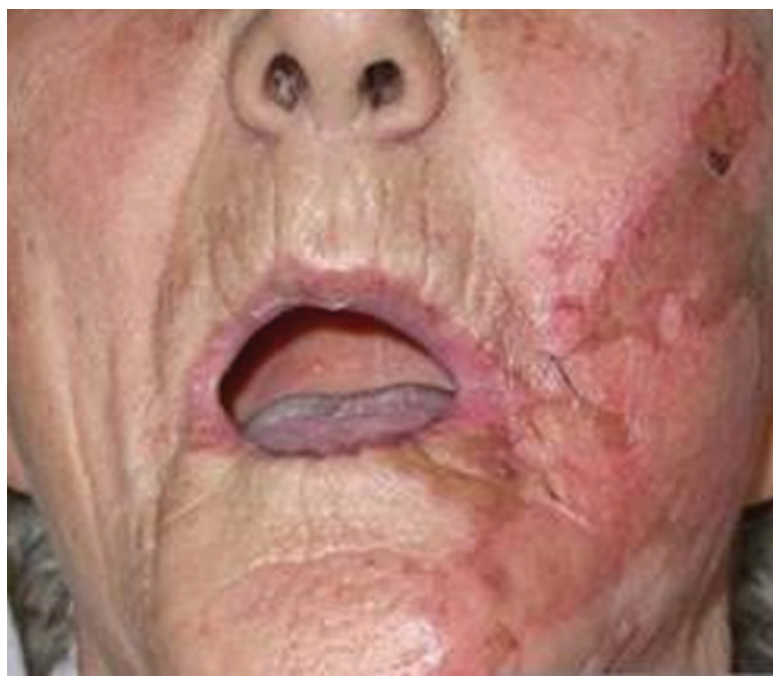

Figure 1. Garlic burn on the left side of face of patient.
The patient was referred to the dermatology clinic for consultation and was diagnosed with a second- degree chemical burn on her face. She was told to apply Bepanthene ${ }^{\circledR}$ cream to the burned areas three times a day, B vitamins (Bemiks $\circledast$ dragee) once a day and to use an analgesic (Vermidon $\circledast$ ). As the result of this treatment, the burned area healed completely within one week (Figure 2). The patient was referred to an oral and maxillofacial surgery clinic because of severe neuralgia pain. It was determined that the pain decreased after local anesthesia was applied in foramen mentale. Then, $1 \mathrm{cc}$ of glycerol was injected in foramen mentale. After this treatment, the patient ceased complaining of pain. When she came in for an examination three years later, she did not complain of pain.

\section{DISCUSSION}

Garlic (Allium sativum) has been recognized as a folk remedy for various illnesses in many cultures for centuries. ${ }^{5-6}$ The medicinal use of garlic dates to at least 3000 B.C., when Egyptian pyramid- builders ate it to prevent illness. Hippocrates used garlic to treat infections, intestinal disorders and chest pain.?

In the modern era, during World War II, the Soviet army used garlic to prevent infections after it had run out of antibiotics, so garlic was called "Russian Penicilin"., 5,7 The antifungal, antiparasitic, antiviral, antimicrobial, antihypertensive, blood glucose lowering, antithrombotic, antimutagenic and antiplatelet properties of this herb have been reported and some of these claims have been

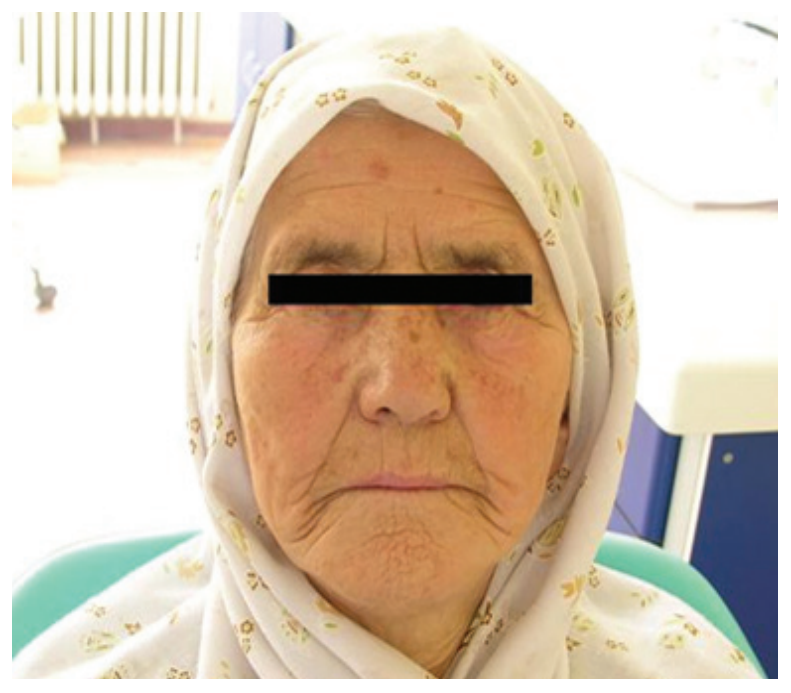

Figure 2. Extraoral appearance of patient after treatment. 
scientifically corroborated. Garlic has also been shown to have a fibrinolytic action and possesses the ability to reduce cholesterol and lipid levels with suggested beneficial effects on atherosclerosis. ${ }^{1,8,9}$ Cases of postoperative bleeding related to platelet dysfunction and spontaneous epidural hematoma also have been reported. ${ }^{7}$

Garlic can cause allergic contact dermatitis. Diallyldisulfide, allicin, and allylpropyldisulfide in garlic are thought to be the principal offending agents, with diallyldisulfide being the strongest sensitizer. ${ }^{2,5,7}$ This component appears to be heat sensitive, so raw garlic causes skin reactions that resemble like burns. ${ }^{7.11}$ In this case report, the patient had a second- degree chemical burn from applying garlic to her face.

Factors such as the concentration and freshness of the garlic, the duration of exposure, the anatomic area of application, pre-existing skin conditions and individual reactivity also appear to contribute to the development of burn wounds. ${ }^{7}$

In this case, while the application of raw garlic redounded to garlic's effect, the fact that it was wrapped in cloth partially reduced direct skin contact and the fact that it was applied for only a hour may have prevented serious skin damage. The reason the patient applied crushed garlic to her face was she was trying to get some relief from the pain that resulted from trigeminal neuralgia.

The physiopathology of trigeminal neuralgia has never exactly been explained, though the disease has been known for centuries. According to the International Association for Study of Pain (IASP), trigeminal neuralgia is a form of neuropathic pain that results in sudden, usually unilateral, brief, intermittent pain that has an lancinating, electrical or burning quality in the distribution areas of one or more branches of the fifth cranial nerve, also called the trigeminal nerve. ${ }^{4,11}$ This pain is typically triggered by daily activities such as eating, talking, or brushing the teeth. Frequently, patients are asymptomatic between episodes. Trigeminal neuralgia may be treated medically and/ or surgically. ${ }^{11,12}$

In this case, a medical treatment (Tegretol $($ ), an alcohol injection in mental foramen and a glycerol injection were given. Following the glycerol injections the patient had no complaint of pain for three years.

\section{CONCLUSIONS}

Health workers should know that herbs like garlic can be used by patients and should be aware of adverse effects of these herbs. For correct diagnosis, while taking the patient's history, the workers should interrogate the patient about the use of these substances. Serious complications and side effects can occur from uncontrolled use of herbal treatment products.

\section{REFERENCES}

1. Borrelli F, Capasso R, Izzo AA. Garlic (Allium sativum L.): Adverse effects and drug interactions in humans. Mol Nutr Food Res 2007;51:1386-1397.

2. Al-Qattan MM. Garlic burns: Case reports with an emphasis on associated and underlying pathology. Burns 2009;35:300-302.

3. Toda K. Operative treatment of trigeminal neuralgia: review of current techniques. Oral Surg Oral Med Oral Pathol Oral Radiol Endod 2008;106:788-805.

4. Dowd FJ. Trigeminal neuralgia. xPharm: The Comprehensive Pharmacology Reference 2008; p. 1-7.

5. Baruchin AM, Sagi A, Yoffe B, Ronen M. Garlic burns. Burns $2001 ; 27: 781-782$

6. Sener G, Satıroḡlu H, Sehirli AÖ, Kaçmaz A. Protective effect of aqueous garlic extract against oxidative organ damage in a rat model of thermal injury. Life Sci 2003;73:81-91.

7. Dietz DM, Varcelotti JR, Stahlfeld KR. Garlic burns: a notso-rare complication of a naturopathic remedy? Burns 2004;30:612-613

8. Ali M, Thomson M, Afzal M. Garlic and onions: their effect on eicosanoid metabolism and its clinical relevance. Prostaglandins Leukot Essent Fatty Acids 2000;62:55-73.

9. Friedman T, Shalom A, Westreich M. Self-inflicted garlic burns: our experience and literature review. Int J Dermatol 2006;45:1161-1163.

10. Rafaat M, Leung AKC. Garlic Burns. Pediatr Dermatol 2000;17:475-476.

11. Peker S, Pamir MN. Tigeminal nevralji tarihçesi. Türk Nöroşirürji Dergisi 2003;13:227-234.

12. Jellish WS, Benedict W, Owen K, Anderson D, Fluder E, Shea JF. Perioperative and long-term operative outcomes after surgery for trigeminal neuralgia: microvascular decompression vs percutaneous balloon ablation. Head Face Med 2008;4:11. 